\title{
Acetic acid-assisted underwater endoscopic mucosal resection for successful resection of sessile serrated lesions
}

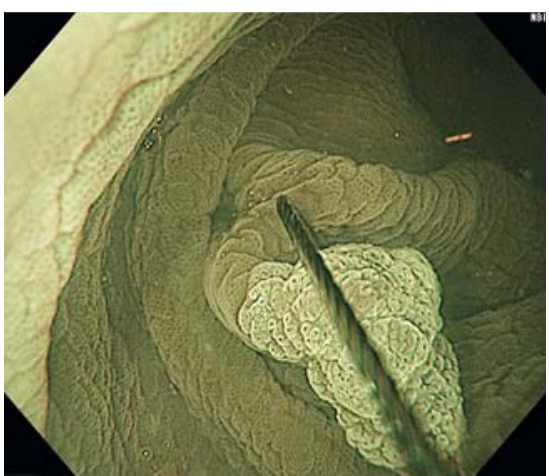

Fig. 1 The margin of the sessile serrated lesion was delineated with acetic acid throughout the snaring process in case 1 .

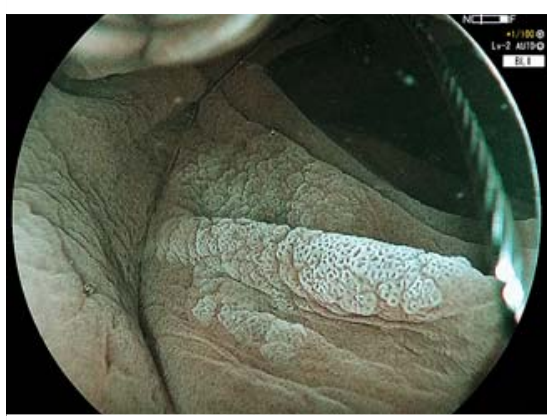

Fig. 2 The margin of the sessile serrated lesion was delineated with acetic acid throughout the snaring process in case 2 .

Underwater endoscopic mucosal resection (UEMR) has become the new standard of endoscopic resection of $\geq 10$ - $\mathrm{mm}$ non-pedunculated colonic polyps [1-4]. It is particularly difficult to delineate the margins of sessile serrated lesions (SSLs). Though submucosal injection of a bluecolored dye mixture (e.g., indigo carmine or methylene blue) is used to enhance these lesions, SSLs tend to expand owing to the injection of the dye. Hence, bigger snares are utilized or more pieces of resection are needed, resulting in bigger defects after removal or non-en bloc resection.

We present two endoscopic resection cases using a new acetic acid-assisted underwater technique for two SSLs. The

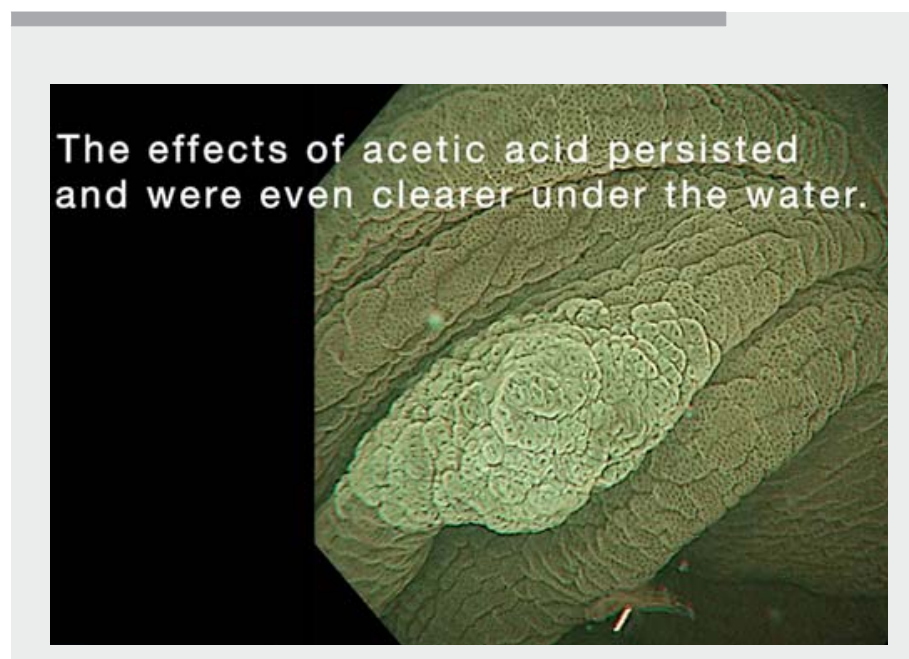

Video 1 Two cases of colonic sessile serrated lesions treated with acetic acid-assisted underwater endoscopic mucosal resection.

lesions were both classified as Paris-Ila; they demonstrated Kudo type II open pits and were located in the right-side colon. The first and second lesions were $12 \mathrm{~mm}$ and $15 \mathrm{~mm}$ in diameter, respectively. In both cases, $10 \mathrm{~mL}$ of $1.5 \%$ acetic acid was applied over the lesion using a syringe. We confirmed the margin of the polyps easily by observing the acetowhitening reaction [5]. The lumen was then filled with saline using the water-jet function of the scope. In contrast to the approach using carbon dioxide, the persistent effect of acetic acid and the lack of mucus production were observed under the water. Thus, the margins of the lesions were clearly delineated throughout the snaring process (>Fig.1, > Fig.2). Furthermore, the color change remained evident despite direct strong application of water onto the polyp. En bloc resection was achieved for both lesions. The persistence of the acetowhitening effect post-resection aided in ensuring no tissues from the lesion were left at the margin of the defect ( $\downarrow$ Video 1 ).

Endoscopy_UCTN_Code_TTT_1AQ_2AD

\section{Acknowledgement}

We would like to thank Editage (www.editage. comwww.editage.com) for English language editing.

\section{Competing interests}

The authors declare that they have no conflict of interest.

The authors

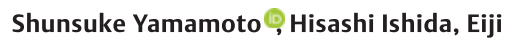
Mita

Department of Gastroenterology and Hepatology, National Hospital Organization Osaka National Hospital, Osaka, Japan

\section{Corresponding author}

Shunsuke Yamamoto, MD

Department of Gastroenterology and Hepatology, National Hospital Organization Osaka National Hospital, 2-1-14 Houenzaka, Chuo-ku, Osaka, 540-0006, Japan shun0515suke@gmail.com 


\section{References}

[1] Binmoeller KF, Weilert F, Shah J et al. "Underwater" EMR without submucosal injection for large sessile colorectal polyps (with video). Gastrointest Endosc 2012; 75: 10861091

[2] Li D-F, Lai M-G, Yang M-F et al. The efficacy and safety of underwater endoscopic mucosal resection for $\geq 10$-mm colorectal polyps: systematic review and meta-analysis. Endoscopy 2021; 53: 636-646

[3] Lupu A, Rivory J, Fabritius M et al. Consecutive cold/hot underwater snaring with a single hybrid snare for resection of large sessile serrated lesions when cold snaring fails. Endoscopy 2020; 52: E241-E242
[4] Choi AY, Moosvi Z, Shah S et al. Underwater versus conventional EMR for colorectal polyps: systematic review and meta-analysis. Gastrointest Endosc 2021; 93: 378-389

[5] Yamamoto S, Varkey J, Bhandari P. Acetoelectronic chromoendoscopy for sessile serrated polyp. Gastrointest Endosc 2021; 93: 267-268

Bibliography

Endoscopy 2022; 54: E508-E509

DOI 10.1055/a-1647-2174

ISSN 0013-726X

published online 15.10 .2021

(C) 2021. Thieme. All rights reserved.

Georg Thieme Verlag KG, Rüdigerstraße 14,

70469 Stuttgart, Germany
ENDOSCOPY E-VIDEOS

https://eref.thieme.de/e-videos

口回 Endoscopy E-Videos is an

open access online section, 靣政: reporting on interesting cases and new techniques in gastroenterological endoscopy. All papers include a high quality video and all contributions are freely accessible online. Processing charges apply (currently EUR 375), discounts and wavers acc. to HINARI are available.

This section has its own submission website at

https://mc.manuscriptcentral.com/e-videos 